\title{
Physical Sciences
}

National Cancer Institute

\section{Source}

National Cancer Institute. Physical Sciences. NCI Thesaurus. Code C16987.

The sciences that focus on the properties and behavior of nonliving matter. 